Palabra Clave (La Plata)

ISSN: 1853-9912

palabraclave@fahce.unlp.edu.ar

Universidad Nacional de La Plata

Argentina

\title{
Classification on the Web: an analysis of Dewey Linked Data
}

Tomoyose, Kazumi; Simionato Arakaki, Ana Carolina

Classification on the Web: an analysis of Dewey Linked Data

Palabra Clave (La Plata), vol. 9, núm. 2, 2020

Universidad Nacional de La Plata, Argentina

Disponible en: http://www.redalyc.org/articulo.oa?id=350562513005

DOI: https://doi.org/10.24215/18539912e092 
Avances de investigación

\title{
Classification on the Web: an analysis of Dewey Linked Data
}

La Clasificación en la web: un análisis de Dewey Linked Data

Kazumi Tomoyose

Universidade Federal de São Carlos, Brasil

kazumi2075@gmail.com

DOI: https://doi.org/10.24215/18539912e092

Redalyc: http://www.redalyc.org/articulo.oa?

Ana Carolina Simionato Arakaki

Universidade Federal de São Carlos, Brasil

acsimionato@ufscar.br

id $=350562513005$

Recepción: 23 Agosto 2019

Aprobación: 12 Noviembre 2019

\begin{abstract}
:
With the availability of information in the World Wide Web its access and retrieval by the users is facilitated, and the Library and Information Science (LIS) field's knowledge and techniques can be applied to this environment in order to help with the process. The present study is descriptive, qualitative and exploratory, based on bibliographical sources, in which it was explored how the Classification discipline interacts with Linked Data, focusing on the analysis of Dewey Linked Data. From four catalogs analyzed, referred to in the literature as adhering to Dewey Linked Data, only two actually has links in their records redirecting to the system. Despite this, its presence in The Linked Open Data Cloud appears as a positive factor in its dissemination, since it boosts its visibility. It is concluded that the Classification discipline allows the thematic standardization of information resources, so that there is uniformity in the Web environment and quality retrieval of information, while promoting interoperability between data in the Linked Data context. The standardization of metadata values using classifications optimizes the representation of information and its retrieval in the Web, while also providing the reuse of data. In addition, studies that align the area of Library and Information Science with the Semantic Web and its technologies can provide new perspectives for the area, as well as contemplate the users' always changing needs, thus, fulfilling the objective of the field.
\end{abstract}

KEYwords: Dewey Linked Data, Dewey Decimal Classification, Linked data, Classification, Information representation.

\section{Resumen:}

Con la disponibilidad de información en la World Wide Web, se facilita su acceso y recuperación por parte de los usuarios, y el conocimiento y las técnicas del campo de la Bibliotecología y Ciencia de la Información (BCI) se pueden aplicar a este entorno para ayudar con el proceso. El presente estudio es descriptivo, cualitativo y exploratorio, basado en fuentes bibliográficas, en que se exploró cómo interactúa la disciplina de Clasificación con los Datos Vinculados, centrándose en el análisis de Dewey Linked Data. De cuatro catálogos analizados, a los que se hace referencia en la literatura como adheridos a Dewey Linked Data, solo dos tienen enlaces en sus registros que redirigen al sistema. A pesar de esto, su presencia en The Linked Open Data Cloud aparece como un factor positivo en su difusión, ya que aumenta su visibilidad. Se concluye que la disciplina de Clasificación permite la estandarización temática de los recursos de información, de modo que haya uniformidad en la Web y recuperación de la información de calidad, al tiempo que promueve la interoperabilidad entre los datos en el contexto de los datos vinculados. La estandarización de los valores de metadatos mediante clasificaciones optimiza la representación de la información y su recuperación en la Web, al tiempo que proporciona la reutilización de datos. Además, los estudios que alinean el área de bibliotecología y ciencia de la información con la web semántica y sus tecnologías pueden proporcionar nuevas perspectivas para el área, así como contemplar las necesidades siempre cambiantes de los usuarios, cumpliendo así el objetivo del campo.

Palabras clave: Dewey Linked Data, Classificación Decimal de Dewey, Datos vinculados, Representación de la información.

\section{INTRODUCTION}

The passage of information resources from analog to digital supports gives users a greater access to the most varied information in various formats, such as audio, video, text, etc. Thus, the need for attention to the 
treatment and organization of information, provided by the skills of Library and Information Science (LIS), becomes even greater, so that the documents can in fact be accessed and retrieved.

At the thematic level of the information resource, the organization can be applied by using classification systems, which provides standardized ways for the accomplishment of the activity. The system studied in this paper is the Dewey Decimal Classification (DDC), created by Melvil Dewey and widely used in libraries for bibliographic organization. To apply it to the Web, the Online Computer Library Center (OCLC) has developed Dewey Linked Data, which has adapted the notations of the DDC to the Linked Data principles, allowing them to be linkable on the Web.

From a descriptive, qualitative and exploratory analysis, the present research aimed to analyze the use of Dewey Linked Data by the Online Public Access Catalogs (OPACs) of libraries and other information centers. By 'use of Dewey Linked Data' it is meant the existence of links between the bibliographic records of the OPACs to the Dewey Linked Data's URIs. The benefits provided by the association between the Semantic Web and Linked Data and the concepts of the area of LIS were also considered.

\section{LITERATURE REVIEW}

When discussing about organization of the informational universe, the discipline of Classification can be of great use. Supporting the field of LIS, Classification covers the tools and techniques involved in the organization of information resources according to its subjects, facilitating its location and identification (Piedade, 1983; Pombo, 1998).

Glushko, Annechino, Hemerly and Wang (2013b, p. 345) defines classification as "the systematic assignment of resources to categories in an organizing system". In other words, it introduces order to a group of resources, supporting the activities in an organizing system, such as "discovery, selection, combination, integration, analysis" (Glushko et al., 2013a, p. 396). Still according to Glushko et al. (2013a, p. 388), "classification creates the structure and support for the interactions that human or computational agents perform", meaning that the classification chosen for an information resource have to make sense to its context and its users in order to be useful, showing the relevance of an appropriate well thought classification process.

In this sense, classification is biased, since it involves a choice that has to be made to better suit and describe an object, such choice being influenced by its purpose, users and the subjectivity of the classifier (Glushko et al., 2013a; Langridge, 2006).

The process of classification follows systems, which are standardized guides to grouping objects according to its similarities and differences in a hierarchical order, supporting information organization by subject and, consequently, information retrieval (Glushko et al., 2013a; Tristão, Fachin, \& Alarcon, 2004). When classifying bibliographic resources, bibliographic classification systems are used, where the DDC system is one of the most widely adopted worldwide (Online Computer Library Center, 2019b).

The DDC was first published in 1876 by Melvil Dewey, a North American librarian from Adams, New York (Piedade, 1983). The design of the DDC started in 1873, when Dewey presented a new scheme for the organization of books in the library of Amherst College, where he worked as an assistant, using symbols (notations) for the representation of each book (Online Computer Library Center, 2019b; Piedade, 1983). The DDC is currently maintained by OCLC, "a global library cooperative that provides shared technology services, original research and community programs for its membership and the library community at large" (Online Computer Library Center, 2019a).

The system uses decimal numbers and only the dot "' symbol for the elaboration of notations, in which the dot must always appear every three digits, in order to facilitate the reading of the same. Therefore, the DDC is classified as a hierarchical classification system of pure notation (Piedade, 1983). 
Dewey divided the human knowledge into ten main classes:

000 Computer science, information \& general works

100 Philosophy \& psychology

200 Religion

300 Social sciences

400 Language

500 Science

600 Technology

700 Arts \& recreation

800 Literature

900 History \& geography

Each class can be divided into ten more, and so forth. For further specification, the main classes, or schedules, can be complemented using one of the six subdivision tables. Thus, the DDC enables the classification and organization of the information resources of a collection by applying notations from the schedules or by creating new notations formed from the combination of the numbers from the schedules and tables.

The DDC can be accessed through WebDewey's subscription or by purchase of the printed versions in translated languages, since the printing of the summary in English has been discontinued (Online Computer Library Center, 2019c, The Dewey Blog, 2017).

However, OCLC offers some features in an open way, such as the introduction of the 23rd edition of the DDC and its glossary, making it easier to instruct professionals unfamiliar with the system (Online Computer Library Center, 2019d). Another feature available free of charge is the training courses, which consist of modules in PDF format on the DDC tables and construction of notations (Online Computer Library Center, 2019d).

With the increasing use of machines as the main means of searching for satisfying users' informational needs, there is a growing concern about how this information is introduced into the Web environment and how it can be properly accessed. So, in 2001 the Semantic Web is presented by Berners-Lee, Hendler, and Lassila (2001) as a way of improving interaction and communication between man and machine, facilitating the processing of data through the use of semantic technologies and standards. According to Shadbolt, Hall, and Berners-Lee (2006, p. 99) “The Semantic Web can't exist without carefully developed and agreed standards, just as the existing Web couldn't have existed without HTTP, ${ }^{1}$ HTML, ${ }^{2}$ and XML, ${ }^{3}$ " stating the fundamentality of technologies such as URIs, ${ }^{4} \mathrm{RDF},{ }^{5}$ and OWL ${ }^{6}$ for the persistence of the Semantic Web. Also know as Web of data, its objective "is to enable computers to do more useful work and to develop systems that can support trusted interactions over the network", as stated by World Wide Web Consortium (2015b, para. 1).

Therefore, the Semantic Web provides an environment where applications can process information in a similar way to the human reasoning, executing 'sophisticated tasks' in order to provide the user with not only information directly correspondent to their search but also related information, supporting a greater use of the web's potential (Isotani \& Bittencourt, 2015, p. 28).

In order to create and explore these links between related data and information presents in the Web, Berners-Lee (2006) defines the Linked Data principles, which are four steps that define a dataset as linkable. First, an URI must be attributed as identification, which is the base of the Semantic Web itself. Second, the use of HTTP URIs, which allows the identification and access of information resources. The third step is to use standardized ways to provide information, such as with RDF and SPARQL. ${ }^{7}$ Finally, the forth step is to make links to other URIs on the Semantic Web, so the data can be found by others (Berners-Lee, 2006). 
By applying the Linked Data principles to the Web it is possible to make links between data derived from people, books, organizations, and anything that expresses information (Bizer, Heath, \& Berners-Lee, 2009). In doing so, the user's experience is improved by the increase of relevant information retrieved, as well as the visibility of the depositors and publishers of the data and documents. In addition to Linked Data there is what is called Linked Open Data, which is Linked Data published under an open license, increasing information access and reach by removing proprietary boundaries (Berners-Lee, 2006; Isotani \& Bittencourt, 2015).

When publishing data, it is important that, just like with any other documents, it is properly described so it can be searched for, accessed and retrieved. That's where metadata plays its part. Metadata are used in the description of different dimensions of a resource, being their structure, content, quality, context, origin, property, and condition, in order to optimize its identification and location (Santos, Simionato \& Arakaki, 2014).

In the LIS field the use of metadata is mainly as bibliographic metadata, which according to Riley (2017, p. 5), "focuses on detailed descriptions of individual items that allow users to locate these items", being, therefore, the application of metadata's objectives and functions to the bibliographic scope.

Alves (2005) defines metadata as sets of attributes, more specifically referential data, which represent the informational content of a resource that may be in a digital medium or not, used to describe and therefore organize information.

Metadata are formed by elements, values and schemes. Metadata elements are the individual categories or classes that hold or support the individual parts of the description of a set of information (Castro, Simonato \& Zafalon, 2016), and are then responsible for individualization and specification of the terms used to precede information from the information resources themselves. The value of a metadata is "the data that is assigned to an element" (Pomerantz, 2015), that is, it is the data from the information resource that fills a particular metadata element field.

As for the schemes, they are defined as sets of elements designed to meet the needs of particular communities (Castro, Simionato \& Zafalon, 2016). They guarantee the structuring of the metadata elements, while also having a markup language that allows the coding of the metadata.

By aligning the use of classification systems to the Semantic Web and to semantic technologies, it is possible to optimize and enhance the representation of information in the digital environment, thus favoring the identification of information resources and their retrieval. In this context, the Dewey Linked Data is developed by OCLC as a way of using the traditional DDC notations in the Semantic Web as Linked Data.

\section{Metodology}

The present work is a descriptive, qualitative and exploratory research, which objective is to identify the adoption of the Dewey Linked Data tool in OPACs. Based on bibliographical sources, the study's scope period was mostly of documents published between 2000 and 2019, due to the development of the Semantic Web in 2001. It was considered materials in the Portuguese, English and Spanish languages on Classification, DDC, Semantic Web, Linked Data, and metadata. The following general and LIS specific databases were used: Brazilian Digital Library of Theses and Dissertations (BDTD), Reference Database of Periodical Articles in Information Science (BRAPCI), Periodicals Portal of Capes, Catalog of Thesis and Dissertations of Capes, Scientific Electronic Library Online (SciELO), Scopus, Google Scholar and Web of Science. The proceedings of the meetings of the International Society for Knowledge Organization (ISKO) and the Brazil's National Meeting of Research in Information Science (ENANCIB) were also consulted. The material was collected in the period of 2018 and 2019.

The keywords used for the search were: "Classification", "classification systems", "Dewey Decimal Classification (DDC)", "Semantic Web", "Linked Data", "Metadata" and "Dewey Linked Data”, in addition to their proper translations to Portuguese and Spanish. The materials selected were the ones that best 
corresponded to the theme and problem of the study in question that met the criteria of the determined time interval and languages.

In order to better understand the applicability of Dewey Linked Data, the OPACs of institutions mentioned in the literature as adherents or partially adherents to the initiative were analyzed. WorldCat was chosen for following the Linked Data principles since 2012, while the OPACs of the British Library, Bibliothèque Nationale de France and Deutsche Nationalbibliothek were chosen from Mitchell and Panzer (2013), who mention them as institutions that uses Dewey Linked Data.

The search tools of the catalogs of each of the information centers were analyzed for the presence or absence of a search filter by DDC notation. Some records were also verified in order to identify the presence of the Dewey Linked Data notations, both in the presentation of the data in its own Web pages as in the records in semantic formats that support Linked Data. The search was done using the notation 020, Library $\&$ information sciences, due to the greater familiarity with the subject.

\section{Results}

In 2009, the DDC 22 was made available in Linked Data, with the addition of DDC 23 and table 2 in 2012 (Mitchell \& Panzer, 2013; Panzer, 2009; 2012). Known as Dewey Linked Data, its initial objectives consisted in providing the summary of the DDC in a machine and human understandable way, by using URIs to identify each one of the classes and by encoding "the classification semantics in RDF/SKOS", making it available under "a widely understood license used in the Semantic Web community" (Mitchell \& Panzer, 2013, p.178).

In order to standardize the identification of each class of the classification system, as well as the relationship between them, it was determined the URI following the pattern: http://dewey.info/\{object-collection\}/ \{object\}/\{snapshot-collection\}/\{snapshot\}/\{about\}. The object collection is mandatory and "specifies the type of the object" (Mitchell \& Panzer, 2013, p. 180), filled by the values “'scheme,' 'table,' 'class,' 'manual,' 'index,' 'summary,' [or] 'id'” (Mitchell \& Panzer, 2013). Optionally, following the object collection is the specific object, succeeded by the snapshot collection and snapshot, which is "used to refer to versions of objects at specific points in time" (Mitchell \& Panzer, 2013, p. 181), such as year, month, and day. Lastly, composing the URI is the about section to direct the user to the information about an object.

The content of the Dewey Linked Data is available in XHTML+RDFa for presentation and human understanding, whereas for machines the same is available in RDF format. The XHTML + RDFa markup language belongs to the eXtensible HyperText Markup Language (XHTML) family, extending XHTML 1.1 and using the attributes of the Resource Description Framework in Attributes Core 1.1 (World Wide Web Consortium, 2015c).

$\mathrm{RDF}$ arises from the difficulty of validating documents in RDF/XML. Despite the flexibility provided by RDF/XML for concept representation, XML or Document Type Definitions (DTDs) schemes are unable to validate them, thus making it difficult to import RDF/XML into other markup languages. Therefore, $\mathrm{RDF}$ allows documents to be enriched from the use of metadata. A set of attributes and parsing rules are defined, but their attributes can contain properties of any RDF vocabularies, allowing an RDFa document to be imported without problems and guaranteeing greater extraction of semantic data (World Wide Web Consortium, 2015a).

XHTML is a redesign of version 4.0 of HyperText Markup Language (HTML 4.0), based on XML. It is a markup language that complies with XML and operates in HTML 4.0, diversifying and increasing the number of platforms on which it is possible to present content (World Wide Web Consortium, 2002).

Thus, with the use of XHTML + RDFa it is possible to present contents in a human understandable way and, at the same time, rich in semantics. In order to be understandable by machines, the summary's content is presented in RDF, in three different serializations: RDF/XML, Turtle, and JSON (Mitchell 
\& Panzer, 2013). The representation of the content is made in RDF/SKOS, where SKOS "is an RDF vocabulary for representing semi-formal knowledge organization systems (KOSs), such as thesauri, taxonomies, classification schemes and subject heading lists" (World Wide Web Consortium, 2009), providing standardization to the use of RDF, assisting it in its objective (World Wide Web Consortium, 2012a; 2014a; 2014b).

Dewey Linked Data adopts the Creative Commons BY-NC-ND 3.0 license (Mitchell \& Panzer, 2013), which allows your data to be shared freely, in any medium or format, provided that you give due credit for the material and do not use it for commercial purposes or distributes other versions created from the original material (Creative Commons, n.d.).

It is possible to search for composite notations in Dewey Linked Data, that is, notations formed by combined numbers of the schedules and auxiliary tables. The search is possible because the data underlying the DDC includes the '765 Synthesized Number Components' field of MARC21, allowing the facets that make up a constructed notation to be isolated (Library of Congress, 2008; Mitchell \& Panzer, 2013).

In the following subsections it is presented the result of the analysis of the OPACs from WorldCat, The British Library, Bibliothéque Nationale de France, and Deutsche Nationalbibliothek, in order to identify and better understand the use of Dewey Linked Data in search tools of information centers.

\subsection{WorldCat}

Considering that WorldCat, maintained by OCLC, follows the Linked Data principles since 2012 (Online Computer Library Center, 2019e), it was sought to analyze the use of Dewey Linked Data in the platform. WorldCat is an online catalog that allows access to bibliographic records of resources on the Web, such as books, DVDs, CDs, articles and digital content (WorldCat, 2019b). Its search tool allows the search for subject with the use of DDC notations, which can be done using the advanced search or the search for the notational number preceded by 'Dewey:' 8

By searching for the notation 020, which corresponds to the Library \& Information science class, records containing 020 as subject or its decimal derivations were retrieved, e.g. 020.92 or 025.431 , showing that the search is not exact.

Each bibliographic record contains a section called 'Linked Data', where the record is presented as linked data in the page itself, as seen in figure 1.

FIGURE 1

Linked data section of a WorldCat bibliographic record

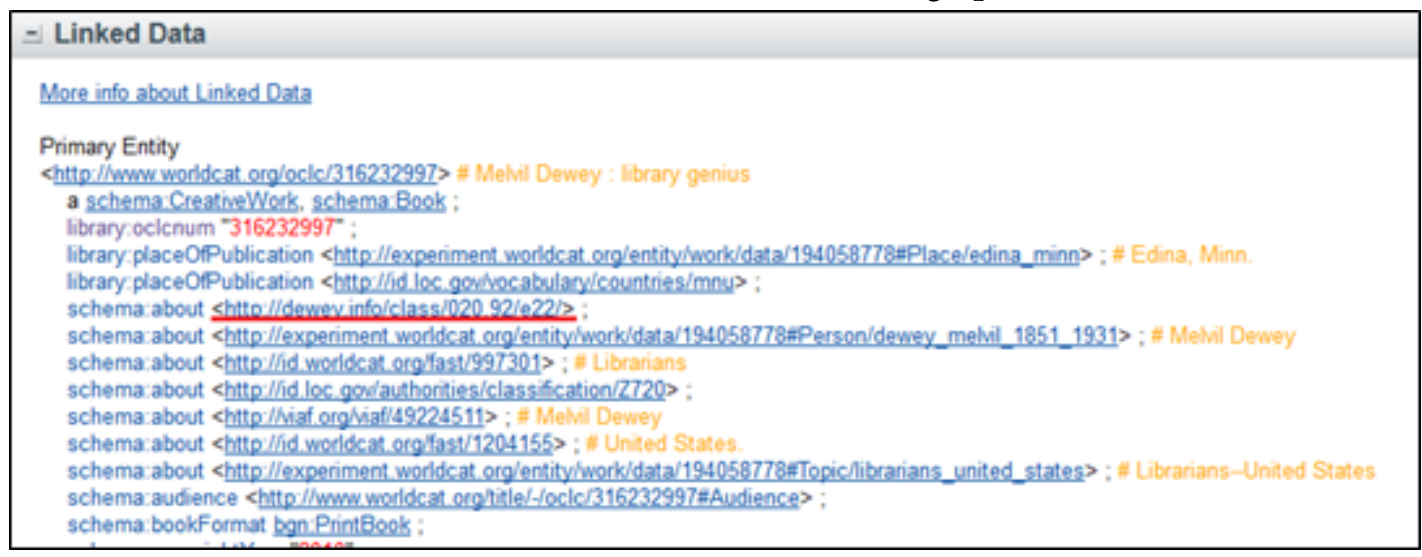

Source: WorldCat (2019a). 
WorldCat also allows the Linked Data record to be downloaded in Turtle, JSON-LD, RDF/XML, NTRIPLES, or HTML+RDFa. It is possible to observe the presence of a dewey.info URI, which creates a link between the WorldCat record and the DDC notation, confirming that the catalog adheres to Dewey Linked Data.

According to Mitchell and Panzer (2013, p. 188) the libraries Bibliothèque Nationale de France, British Library, and Deutsche Nationalbibliothek uses Dewey Linked Data in their bibliographic records to "facilitate machine-assisted categorization and support discovery in the Semantic Web environment". From this, their OPACs were analyzed in order to verify if, since then, the Dewey Linked Data has been adopted in a linkable way.

\subsection{British Library}

When accessing the British Library's catalog it is possible to search for notation numbers with the advanced search tool by selecting the 'Subject' field and entering in the search field the DDC number, preceded by the expression 'Dewey:' 9 .

The search can also be performed from the bibliographic record itself, by selecting its notation number, as seen in figure 2 .

FIGURE 2

Notation search from a British Library bibliographic record



Source: British Library (n.d.).

The British Library catalog allows the search of subjects by notational numbers of the DDC, under which the information resources are classified. However, it was not possible to identify the use of the URIs of the terms from the Dewey Linked Data summary itself.

The British Library has also developed the British National Bibliography Linked Data Platform (BNB Linked Data Platform), which "provides access to the British National Bibliography published as linked open data and made available through SPARQL services" (The British Bibliography as Linked Open Data, 
n.d., parr. 1). The DDC notations are also present in the records of BNB Linked Data Platform, but when analyzing the RDF/XML format of a record, it is possible to ascertain that it does not redirect to an URI of Dewey Linked Data.

The DDC number is used in the British Library for identification of the document's subject, being linked to the notation's URI in the BNB Linked Data Platform system itself, and not to Dewey Linked Data. The page of the notation offers information on its type, being 'TopicDDC' and 'Concept', and also does not include a link to Dewey Linked Data.

\subsection{Bibliothèque Nationale de France}

As in the British Library online collection, it is possible to search for DDC notations in the general library of the Bibliothéque Nationale de France, the National Library of France. That is possible by searching for the number in the 'subject, genre or form' field.

When searching for bibliographic records classified in $020,7452^{10}$ results were obtained. It should be noted, however, that all records with the 020 notation and their decimal derivatives were also retrieved, even when performing the search by the exact expression (Expression exacte). ${ }^{11}$ This allows a greater number of results to be obtained, but the lack of precision in the search can lead to a failure in the information retrieval.

One of the ways to retrieve records more precisely is by selecting the symbol next to the notational number in a bibliographic record, indicated in red in figure 3.

FIGURE 3

Bibliothèque Nationale de France's bibliographic record

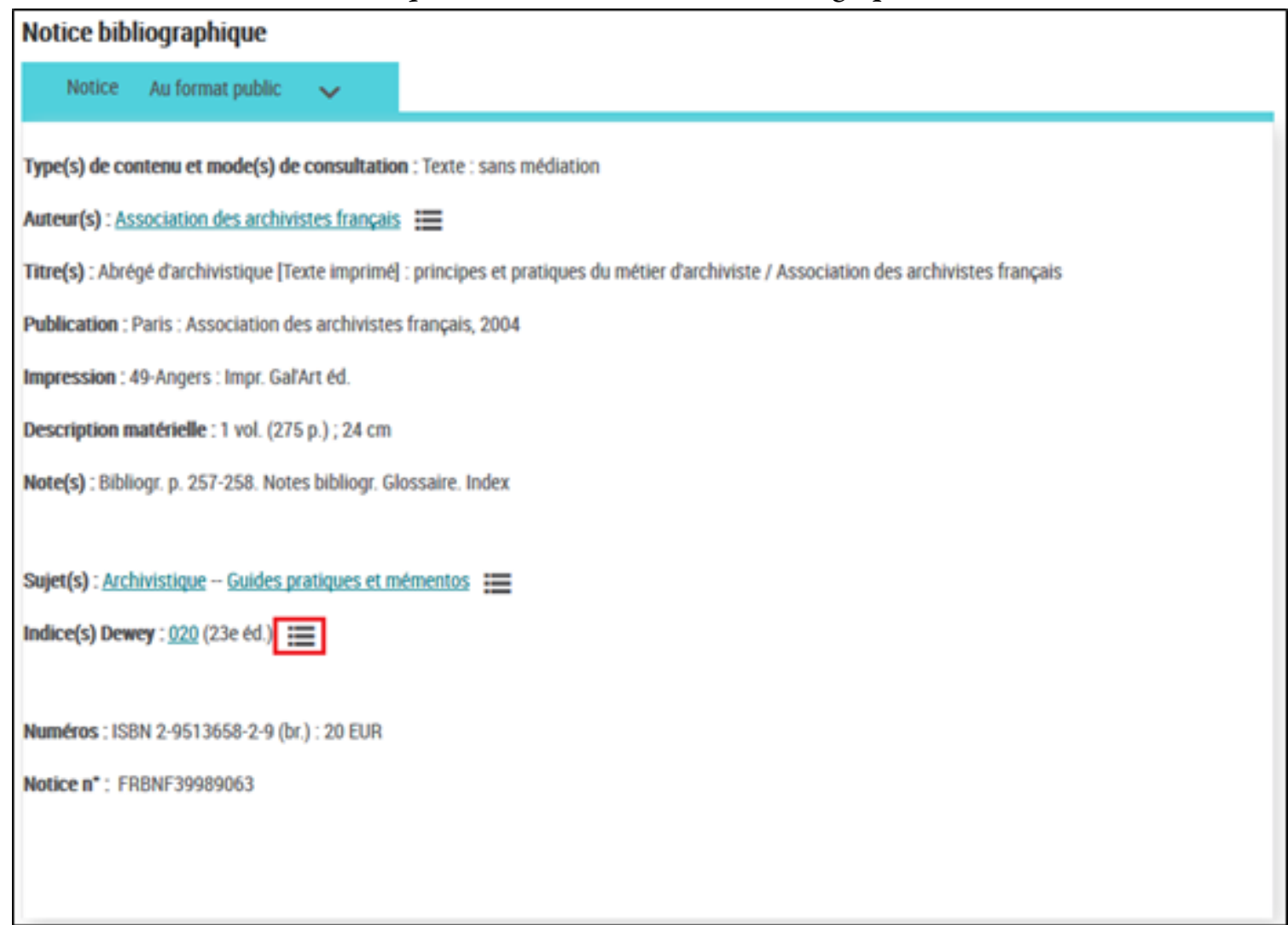


In doing so, a new, more specific notation search is generated by the system, considering both notation number and DDC edition. For the 020 notation, it was possible to retrieve $297^{12}$ bibliographic records using this method.

Furthermore, information about DDC notations can be viewed by selecting them in the bibliographic records, presented in two formats: public and Intermarc. Some of the information that can be found are: classification number; DDC edition; class name; what to classify under the notation, as well as where to classify related subjects; 'rejected forms'; control number; and dates of creation and update of the registry.

Despite directing from the bibliographic records to information regarding the DDC number, it was not possible to identify a link to the summary in Linked Data of the DDC.

\subsection{Deutsche Nationalbibliothek}

The Deutsche Nationalbibliothek, the German National Library, allows the search in its catalog for DDC notations through advanced search by filling the field 'DDC-Notation' with the notation number of the desired subject. The search can also be performed by using the expression 'ddc all' before the notation number.

The search resulted in $509^{13}$ bibliographic records, having retrieved all the records which classification is under the 020 notation and derived decimal notation. For exact search, the notational number should be preceded by the expression 'dcs ='.

Repeating the search for the exact notation 020 it was possible to retrieve $287^{14}$ bibliographic records. Once you access a bibliographic record, you can see on the right side the 'actions' bar, which includes, among others, the options to download the record in MARC21 XML, RDF (Turtle), and BIBFRAME. Opening a record in RDF (Turtle) provides access to its RDF structure, presented in figure 4 below. 
FIGURE 4

Deutsche Nationalbibliothek's bibliographic record for the work

Archive heute - vergangenheit für die Zukunft, in RDF (Turtle)

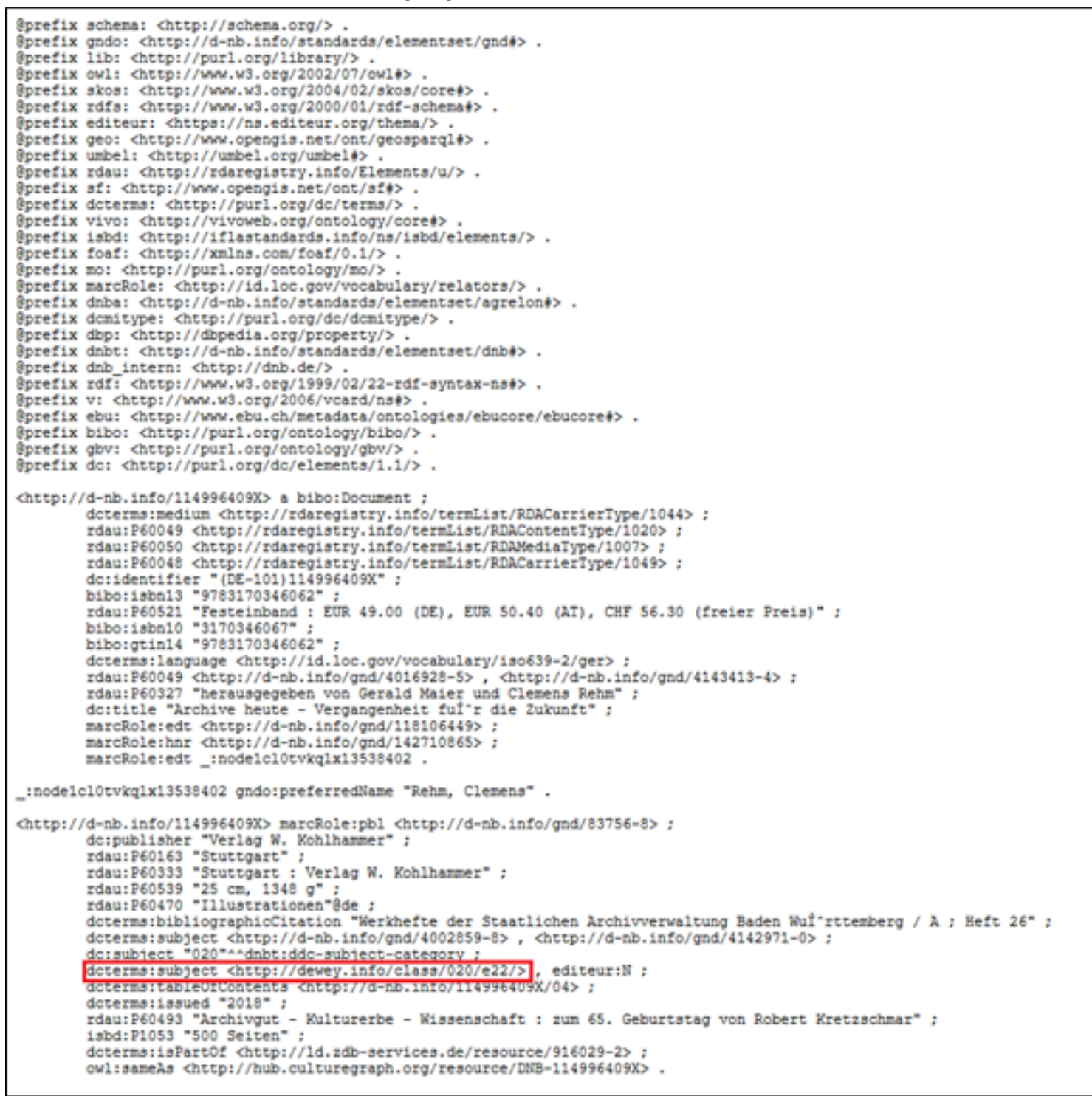

Source: Deutsche Nationalbibliothek (n.d.).

In red is highlighted the section corresponding to the linking of the DDC notation to its corresponding URL in the Linked Data summary, showing that the catalog actually has links to Dewey Linked Data. The Deutsche Nationalbibliothek also provides another resource for subject search based on DDC notations. It is a research tool intended only for the search by notations called WebDewey Search, which allows you to search for the exact notational numbers you want and to navigate through the notations in a hierarchical way, including records from the German libraries: Deutsche Nationalbibliothek (DNB), Gemeinsamer Bibliotheksverbund (GBV), HeBIS Verbundkatalog (HeBIS), SUB Göttingen (SUB), Südwestdeutscher Bibliotheksverbund (SWB), and FU Berlin (FUB) (WebDewey Search, n.d.).

Compared to the other catalogs analyzed, the Deutsche Nationalbibliothek provides greater possibilities of research and navigation, facilitating the search process. It was possible to identify the linkage of notations to Dewey Linked Data, and in addition, the Deutsche Nationalbibliothek incorporates Dewey Linked Data summary's data into its own search tool, WebDewey Search. 
In this way, from the four catalogs investigated, only the WorldCat and the Deutsche Nationalbibliothek's catalogs incorporate links to Dewey Linked Data. The other two libraries indicated by Mitchell and Panzer (2013), the British Library and the Bibliotheque nationale de France, despite using the summary of DDC to categorize their own records, do not use links to associate the classification terms to the terms in Dewey Linked Data at http://dewey.info, thus not taking complete part of the initiative.

In August 2017 OCLC announced on the Dewey blog, available at http://ddc.typepad.com/025431/, the discontinuation of new prints in English of the DDC, while the translations will still be available for purchase through its partners (Jones, 2017). The decision was made because of the constant updating that the classification system suffers in order to adapt to the user's classification needs, which makes the printed editions quickly obsolete.

With the new change of DDC to the digital environment, the next logical step is to use its summary in Linked Data, as its application becomes even more viable, generating a better use of the DDC-related services offered by OCLC.

Since the purpose of classification systems is to provide a standardization of the thematic representation of information resources, it is possible to say that they act on the value level of metadata by providing notational numbers. In the semantic scope of the Web, the standardization of these values optimizes the retrieval and discovery of the information, also standardizing the relations provided by Linked Data. In this way, it is noted that the Dewey Linked Data satisfies this purpose, allowing their notations to be applied as metadata values in a linkable way.

The interface of the Dewey Linked Data could not be evaluated, since its web page is currently, in August of 2019, out of service, which can also be an impediment to its adoption by information centers. However, its visibility and use can be boosted due to its presence in The Linked Open Data Cloud (LOD Cloud), a diagram of datasets that are published following the Linked Data principles, illustrating the relationships between each dataset, as show in figure 5 (McCrae et al., n.d.). 
FIGURE 5

The Linked Open Data (LOD) Cloud from 29 March 2019

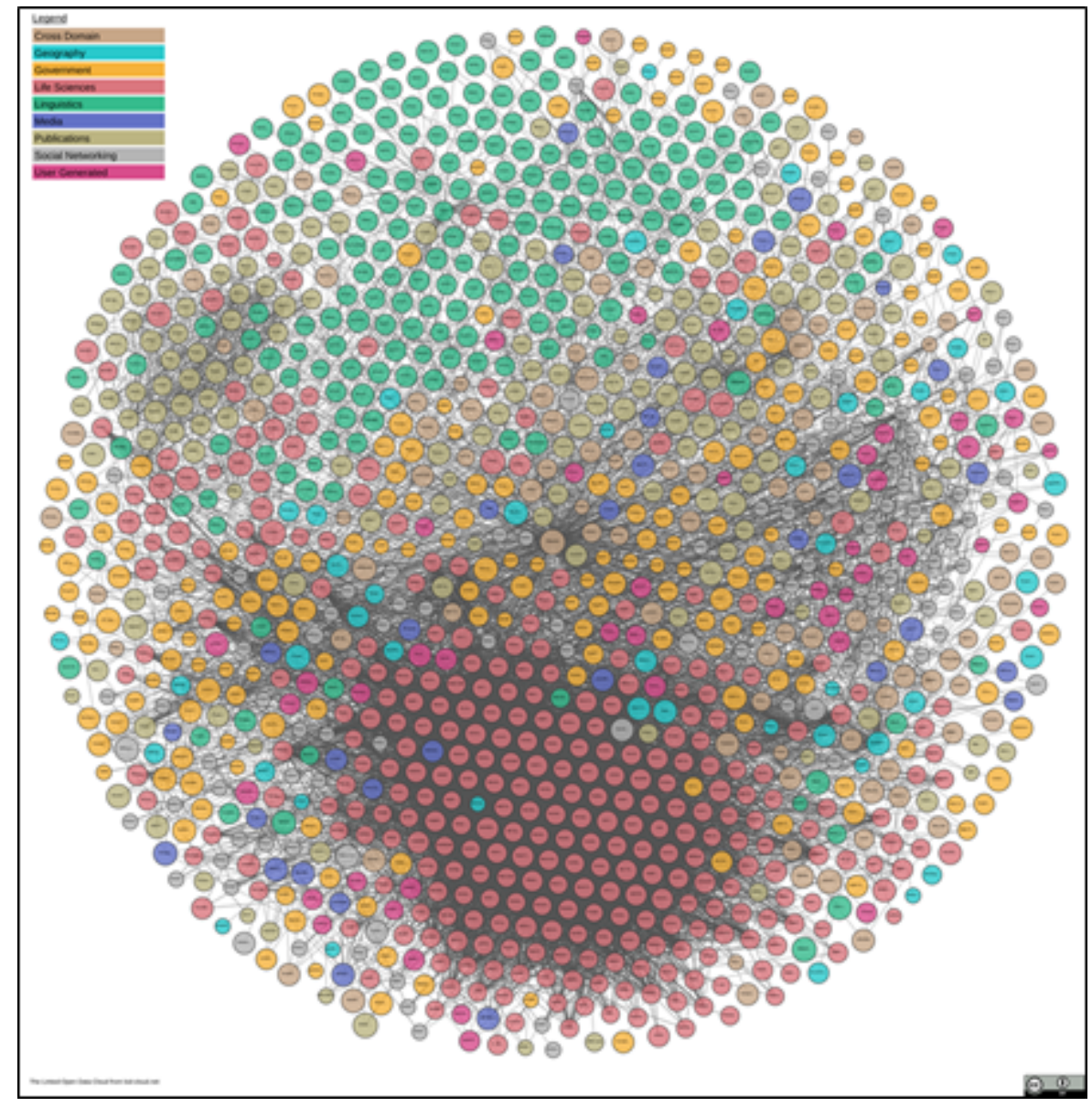

Source: McCrae (n.d.).

From the analysis of the literature and results obtained, section 5 presents the reflections on the relationship between Classification and Linked Data principles and their implication to information centers and to the area of LIS.

\section{ConcLusions}

From the research conducted it is possible to state that data representation is essential on the Web, since it is representation that allows finding and retrieving information in the environment. The Classification discipline allows the standardization in the thematic context of the information resource, so that there is uniformity in the Web environment and quality retrieval of information. Classification is also essential in the Linked Data context, since it facilitates interoperability between data.

By using classification systems, in this case the DDC, in the Semantic Web it is possible to repurpose the already established notations as a standard way of representing information resources according to their themes. Combined with Linked Data, the creation of links between related objects is provided, improving information retrieval. That is possible by reusing the notations as metadata values. Adopting Dewey Linked Data as a scheme to describe the subjects of information resources in OPACs helps to identify and locate them, thereby improving their retrieval as well as the user's experience.

Deutsche Nationalbibliothek' 
Its low rate of adherence might be explained by the fact that the web page is out of service, without a prediction of going back online (which also difficulted the present investigation process), in addition to not being much discussed by the LIS community. One possibility of countering the situation is to carry out more discussions and researches on Classification in the Semantic Web environment, which can innovate the way libraries operate and relate to the Web, better contemplating the informational needs of a society currently marked by the Web and the technological advances, and thus properly serving the user. Greater collaboration and dialogue between different communities can bring mutual benefits by providing new elements that contribute to what the other needs, optimizing all areas involved. We suggest as a possible subject of study for future researches the investigation of different tools, such as vocabularies, applied to the Web, in order to better understand and show the flexibility of instruments developed in the LIS domain.

\section{Agradecimientos}

To the São Paulo Research Foundation (Fundação de Amparo à Pesquisa do Estado de São Paulo [FAPESP]) for the research funding (Process 2016/20665-5).

\section{ReferenCES}

Alves, R. C. V. (2005). Metadados como elementos do processo de catalogação [Metadata as elements of the cataloging process] (Doctoral dissertation). Universidade Estadual Paulista, Marília. Retrieved from http://hdl.handle.ne $\mathrm{t} / 11449 / 103361$

Berners-Lee, T. (2006). Linked data. Retrieved from https://www.w3.org/DesignIssues/LinkedData.html

Berners-Lee, T., Hendler, J., \& Lassila, O. (2001). The semantic web. Scientific American, 284(5), 28-37.

Bibliothèque Nationale de France. (n.d.). Abrégé d'archivistique (Texte imprimé). Retrieved from https://catalogue.b nf.fr/ark:/12148/cb39989063w

Bizer, C., Heath,T. \& Berners-Lee, T. (2009). Linked data: the story so far. International journal on semantic web and information systems, 5(3), 1-22. doi: https://eprints.soton.ac.uk/271285/

British Library. (n.d.). Exploring emotional web experience: more than just usability and good design. Retrieved from http://explore.bl.uk/primo_library/libweb/action/display.do?frbrVersion=2\&tabs=moreTab\&ct=displ ay\&fn $=$ search\&doc $=$ BLL01015914612\&ind $x=1 \&$ recIds $=$ BLL01015914612\&recIdxs=0\&elementId =0\&re nderMode $=$ poppedOut\&displayMode $=$ full $\&$ frbrVersion $=2 \& \mathrm{frbg}=\& \& \mathrm{vl}(488279563 \mathrm{UIO})=$ any $\& \mathrm{dscnt}=0 \&$ scp.scps=scope\%3A\%28BLCONTENT\%29\&tb=t $\& v i d=B L V U 1 \&$ mode $=$ Basic\&srt=rank\&tab=local_tab\& $\mathrm{dum}=\operatorname{true} \& \mathrm{vl}($ freeText 0$)=$ exploring\%20emotional\%20 $\mathrm{web} \% 20$ experience\&dstmp $=1545776924114$

Castro, F. F., Simionato, A. C., \& Zafalon, Z. R. (2016). Aspectos relacionais entre ontologia e metadados: consideraçôes interdisciplinares [Relational aspects between ontology and metadata: interdisciplinary considerations]. Proceedings from the 17th Encontro Nacional De Pesquisa em Ciência da Informação. PPGCI/UFBA, Salvador da Bahia. Retrieved from http://www.ufpb.br/evento/lti/ocs/index.php/enancib2016/enancib2016

Creative Commons. (n.d.). Attribution-Non Comercial-Noderivs 3.0 Unported (CCBY-NC-ND 3.0). Retrieved from https://creativecommons.org/licenses/by-nc-nd/3.0/

De Virgilio, R.; Giunchiglia, F. \& Tanca, L. (Ed.). (2010). Semantic web information management: a model-based perspective. Berlin: Springer Science \& Business Media.

Deutsche Nationalbibliothek. (n.d.). Archive heute - vergangenheit für die Zukunft. Retrieved from http://d-nb.info /114996409X

Glushko, R. J. et al. (2013a). Classification: assigning resources to categories. In R. J. Glushko (Ed.), The discipline of organizing (pp. 387-436). (n.p.): The MIT Press.

Glushko,R. J., Annechino, R., Hemerly, J., Wang, L. (2013b). Classification: describing resource classes and types. In R. J.Glushko (Ed.), The discipline oforganizing (pp. 337-375). (n.p.): The MIT Press. 
Internet Engineering Task Force. (2014). Hypertext Transfer Protocol (HTTP/1.1): message syntax and routing. Retrieved from https://www.ietf.org/rfc/rfc7230.txt

Isotani, S., \& Bittencourt, I. I. (2015). Dados abertos conectados [Linked open data]. São Paulo: Novatec.

Jones, S. (2017). Dewey print editions. Retrieved from http://ddc.typepad.com/025431/2017/08/dewey-print-editi ons.html

Langridge, D. (2006). Classificação: abordagem para estudantes de biblioteconomia [Classification: approach for librarianship students]. Rio de Janeiro: Interciência.

Library of Congress. (2008). 765 synthesized number components (R). Retrieved from https://www.loc.gov/marc/cla ssification/cd765.html

McCrae, J. P. et al. (n. d.). The linked open data cloud diagram. Retrieved from http://lod-cloud.net/

Mitchell, J. S., \& Panzer, M. (2013). Dewey linked data: Making connections with old friends and new acquaintances. JLIS.it, 4(1), 177-199. doi: http://dx.doi.org/10.4403/jlis.it-5467

Online Computer Library Center. (2019a). About. Retrieved from https://www.oclc.org/en/about.html

Online Computer Library Center. (2019b). Dewey services: Dewey Decimal Classification summaries - a brief introduction to the Dewey Decimal Classification system. Retrieved from https://www.oclc.org/en/dewey/featu res/summaries.html

Online Computer Library Center. (2019c). Dewey services: overview. Retrieved from https://www.oclc.org/en/dew ey.html

Online Computer Library Center. (2019d). Dewey services: resources. Retrieved from https://www.oclc.org/en/dew ey/resources.htmll

Online Computer Library Center. (2019e). OCLC linked data. Retrieved from https://www.oclc.org/developer/de velop/linked-data.en.htmll

Panzer, M. (2012). DDC 23 released as linked data at dewey.info. Retrieved from http://ddc.typepad.com/025431/2 012/06/ddc-23-released-as-linkeddata-at-deweyinfo.htmll

Panzer, M. (2009). Dewey summaries published as Linked Data. Retrieved from http://ddc.typepad.com/025431/20 09/08/dewey-summaries-published-aslinked-data.html

Piedade, M. A. R. (1983). Introdução à teoria da classificação [Introduction to classification theory]. Rio de Janeiro: Interciência.

Pombo, O. (1998). Da classificação dos seres à classificação dos saberes [From the classification of beings to the classification of knowledge]. Revista da Biblioteca Nacional de Lisboa, 2, 19-33.

Pomerantz, J. (2015). Metadata. Cambridge: The MIT Press.

Riley, J. (2017). Understanding metadata: what is metadata, and what is it for?. Baltimore: NISO. Retrieved from htt ps://groups.niso.org/apps/group_public/download.php/17446/Understanding\%20Metadata.pdff

Santos, P. L. V. A. C., Simionato, A. C. \& Arakaki, F. A. (2014). Definição de metadados para recursos informacionais: apresentação da metodologia BEAM [Metadata definition for information resources: presentation of the BEAM methodology].Informação \& informação, 19(1), 146-163. Retrieved from http://hdl.handle.net/11449/114736

Shadbolt, N., Hall, W., \& Berners-Lee, T. (2006). The Semantic Web revisited. IEEE intelligent systems, 21(3), 96-101. Retrieved from https://eprints.soton.ac.uk/262614/1/Semantic_Web_Revisted.pdf

The British Bibliography as Linked Open Data. (n.d.). Welcome to bnb.data.bl.uk. Retrieved from http://bnb.data.b l.uk/

The Dewey Blog. (2017). Dewey print editions. Retrieved from http://ddc.typepad.com/025431/2017/08/dewey-pr int-editions.html

Tristão, A. M. D.; Fachin, G. R. B. \& Alarcon, O. E. (2004). Sistema de classificação facetada e tesauros: instrumentos para organização do conhecimento [Faceted classification system and thesaurus: tools for knowledge organization]. Ciência da informação, 33(2), 161-171. Retrieved from http://www.scielo.br/scielo.p hp?pid=S0100-19652004000200017\&script $=$ sci_abstract\&tlng=pt 
WebDewey Search. (n.d.). Hilfe zu WebDewey Search. Retrieved from https://deweysearchde.pansoft.de/webdewey search/help.html

World Wide Web Consortium. (2002). XHTML 1.0 the extensible hypertext markup language (second edition). Retrieved from https://www.w3.org/TR/2018/SPSD-xhtml1-20180327/

World Wide Web Consortium. (2009). SKOS Simple Knowledge Organization System primer. Retrieved from https: //www.w3.org/2006/07/SWD/SKOS/primer/primer-20090427.htmll

World Wide Web Consortium. (2012a). Introduction to SKOS. Retrieved from https://www.w3.org/2004/02/skos /intro

World Wide Web Consortium. (2012b). Web Ontology Language (OWL). Retrieved from https://www.w3.org/20 $01 /$ sw/wiki/OWL

World Wide Web Consortium. (2013). SPARQL 1.1 overview. Retrieved from https://www.w3.org/2001/sw/wiki /SPARQLL

World Wide Web Consortium. (2014a). RDF 1.1 primer. Retrieved from http://www.w3.org/TR/2014/NOTE-rd f11-primer-20140624/

World Wide Web Consortium. (2014b). Resource Description Framework (RDF). Retrieved from https://www.w3. org/2001/sw/wiki/RDF

World Wide Web Consortium. (2015a). RDFa Core 1.1 - third edition: syntax and processing rules for embedding RDF through attributes. Retrieved from http://www.w3.org/TR/2015/REC-rdfa-core-20150317/

World Wide Web Consortium. (2015b). Semantic web. Retrieved from https://www.w3.org/standards/semanticw $\mathrm{eb} /$

World Wide Web Consortium. (2015c). XHTML+RDFa 1.1 - third edition: support for RDFa via XHTML modularization. Retrieved from http://www.w3.org/TR/2015/REC-xhtml-rdfa-20150317/

World Wide Web Consortium. (2015d). XML essentials. Retrieved from https://www.w3.org/standards/xml/core

WorldCat (2019a). Melvil Dewey: library genius. Retrieved from https://www.worldcat.org/title/melvil-dewey-libra rygenius/oclc/768429359\&referer=brief_results

WorldCat. (2019b). WorldCat. Retrieved from https://www.worldcat.org/

\section{Notas}

1 Search link: https://www.worldcat.org/search?qt=worldcat_org_all\&q=dewey\%3A020

2 Search link:

http://explore.bl.uk/primo_library/libweb/action/search.do?fn=search\&ct=search\&initialSearch=true\&mode=Adv anced $\&$ tab $=$ local_tab\&ind $=1 \&$ dum $=$ true\&srt $=$ rank\&vid $=B L V U 1 \&$ frbg $=\& \mathrm{tb}=\mathrm{t} \& \mathrm{vl} \% 282084770715$ UI0\% $29=\mathrm{s}$ ub\&vl\%282084770715UI0\%29=title\&vl\%282084770715UI0\%29=sub\&vl\%281UIStartWith0\%29=exact\&vl\%28 freeText0\%29=Dewey\%3A020\&vl\%28boolOperator0\%29=AND\&vl\%282084770717UI1\%29=any\&vl\%2820847 70717UI1\%29=title\&vl\%282084770717UI1\%29=any\&vl\%281UIStartWith1\%29=contains\&vl\%28freeText $1 \% 29$ $=\& \mathrm{vl} \% 28$ boolOperator $1 \% 29=$ AND\&vl\%282084770716UI2\%29=any\&vl\%282084770716UI2\%29=title\&vl\%282 084770716UI2\%29=any\&vl\%281UIStartWith2\%29=contains\&vl\%28freeText2\%29=\&vl\%28boolOperator2\%29 $=$ AND\&vl\%282084770721UI3\%29=all_items\&vl\%28drStartDay4\%29=00\&vl\%28drStartMonth4\%29=00\&vl\%2 $8 \mathrm{drStart} Y$ ear $4 \% 29=$ Year\&vl\%28drEndDay4\%29=00\&vl\%28drEndMonth4\%29=00\&vl\%28drEndYear4\%29=Year \&scp.scps=scope\%3A\%28BLCONTENT\%29\&Submit=Search

3 Search result from 01 july 2019. Search link: https://catalogue.bnf.fr/search.do?mots0=SUJ;-1;0;020\&mots1=ALL;0 ;0;\&\&pageRech=rav

4 Search link: https://catalogue.bnf.fr/search.do?mots0=SUJ;-1;2;020\&mots1=ALL;0;0;\&\&pageRech=rav

5 Search result from 01 july 2019.

6 Search result from 01 july 2019. Search link: https://portal.dnb.de/opac.htm?index=ddc\&term=020\&operator=and \&index $=$ per\&term $=$ \&operator $=$ and \&index $=$ inh\&term $=$ \&operator $=$ and\&index $=$ sw\&term $=$ \&operator $=$ and \&inde $\mathrm{x}=$ jhr\&term $=\&$ index $=\mathrm{wvn} \& \mathrm{wvnStart}=\& \mathrm{wvnEnd}=12.11 .2019 \&$ method $=$ enhancedSearch

7 Search result from 01 july 2019. Search link: https://portal.dnb.de/opac.htm?query=dcs\%3D\%22020\%22\&method= simpleSearch\&cqlMode=true 
8 "The Hypertext Transfer Protocol (HTTP) is a stateless application-level request/response protocol that uses extensible semantics and self-descriptive message payloads for flexible interaction with network-based hypertext information systems" (Internet Engineering Task Force, 2014, parr. 1).

9 Hypertext Markup Language (HTML) is used for presenting information on the Web (Isotani \& Bittencourt, 2015).

10 Extensible Markup Language (XML) "is a simple text-based format for representing structured information", but with more strict syntax rules than HTML, focusing on the interoperability of the data (De Virgilio, Giunchiglia, \& Tanca, 2010; World Wide Web Consortium, 2015d, para. 1).

11 A Uniform Resource Identifier (URI) is a way of uniquely identifying a resource, abstract or physical, with universally understandable characters (Isotani \& Bittencourt, 2015).

12 "The Resource Description Framework (RDF) is a framework for expressing information about resources", allowing applications to exchange information without 'loss of meaning' (World Wide Web Consortium, 2014a, para. 1).

13 "Web Ontology Language (OWL) is a Semantic Web language designed to represent rich and complex knowledge about things, groups of things, and relations between things. OWL is a computational logic-based language such that knowledge expressed in OWL can be exploited by computer programs" (World Wide Web Consortium, 2012b, para. 1).

14 SPARQL is a query language for RDF, and "can be used to express queries across diverse data sources, whether the data is stored natively as RDF or viewed as RDF via middleware” (World Wide Web Consortium, 2013, parr. 1). 